\title{
Method of Electricity Supply Reliability Need Assessment for Multi-type Power Users Area
}

\author{
Yihao Zeng ${ }^{1}$, Lin Guan ${ }^{1}$, Han $\mathrm{Wu}^{2}$ \\ ${ }^{1}$ School of Electrical Power, South China University of Technology, Guangzhou, China \\ ${ }^{2}$ Fujian Electric Power Research Institute, Fuzhou, China \\ Email: lopezzeng@qq.com
}

Received April, 2013

\begin{abstract}
With electric power outage influence on different type users analyzed, indexes for assessing supply reliability need level is designed. Based on fuzzy evaluation method, a regional power supply reliability level assessment method which utilizes qualitative data is presented.
\end{abstract}

Keywords: Power Supply Reliability Need Assessment; Indexes for Need Assessment of Supply Reliability; Regional Supply Reliability Needs

\section{Introduction}

Power supply enterprises value reliability management, but need of reliability lacks of attention. Analysis and assessment of power users reliability need is nearly blank, so power enterprises can only obtain insufficient need information via users' load rank. Otherwise, for the reason that projects for improving reliability cost money and power outage causes users' loss, it is suggested that supply companies provide customers suitable reliability according to their requirements and charge them price of reliability [1-3]. A regional power supply reliability need assessment method which utilizes qualitative data is presented in this paper, and it may be complementary reference for distribution project feasibility analysis.

\section{Power Outage Influence on Important Users}

Here is a brief analysis of outage influence on typical users.

1) Towards high-rise residential buildings, power failure causes worst effect on high-rise ones, compared to low-rise ones:

- Due to the existence of elevators, high-rise flats require higher reliability. Because of a power failure people will be inconvenient to go upstairs and downstairs, even will be trapped in elevator. Although interruption duration is short, it takes quite long to restart an elevator by relevant administrator. From the above, high-rise housing can endure neither long-hours power loss nor frequent interruption.
- $\quad$ Subject to press condition provided by water supply company, departments on the sixth floor and above have water supplied in secondary water supply mode with pumps and tanks. After a short-time power outage, water supply will be interrupted.

2) Towards numerous industrial customers, their load rate is rather high and single user consumers much electric energy. Power interruption causes industrial enterprises' abnormal downtime and production reduction, meanwhile sale income of power supply company will be affected. Otherwise, restart cycle of some industrial equipments and production processes is rather long, like electrolytic aluminium and Iron \&steel smelting, their owners ask for low interrupt frequency.

3) Towards commercial users, there are several sort of load including lighting, elevator running, heating \& cooling via air conditioner, checkout. Any sort of load listed above should not be interrupted even for a short while, otherwise commercial operation will be severely affected. What is more, since some heavy industrial customers have a large proportion of load ranked level 1 and level 2, sudden power outage may well result in personal injury.

4) Roads in city are divided into 4 grades, among them main road and fast speed road are in strong position of traffic. Once traffic lights turn blind due to power loss, it is probable to have traffic jams and accidents.

5) Government departments take political, economic, cultural functions and so on, so they are surly of special importance. Therefore, government users' supply reliability needs to be guaranteed. 


\section{Indexes of Need Assessment of Supply Reliability}

Towards high-rise residential building users' needs of reliability, HP and HC indexes are defined below:

$$
\begin{gathered}
H P=\frac{C_{R}}{C_{S}} \\
H C=\frac{C_{H}}{C_{R}}
\end{gathered}
$$

where $C_{R}, C_{S}, C_{H}$ are annual residential electricity consumption, annual total electricity consumption, annual electricity consumption of high-rise residential building users in specific area, respectively.

Towards commercial users, CP and CC indexes are defined below:

$$
\begin{gathered}
C P=\frac{C_{C}}{C_{S}} \\
C C=\frac{V_{C}}{C_{C}}
\end{gathered}
$$

where $C_{C}, V_{C}$ are annual commercial electricity consumption, annual commercial value of production in specific area, respectively.

Towards industrial users, IP and IC indexes are defined below:

$$
\begin{array}{r}
\mathrm{IP}=\frac{\mathrm{C}_{I}}{\mathrm{C}_{\mathrm{S}}} \\
\mathrm{IC}=\frac{\mathrm{V}_{I}}{\mathrm{C}_{I}}
\end{array}
$$

where $C_{I}, V_{I}$ are annual industrial electricity consumption, annual industrial value of production in specific area , respectively.

Towards traffic light users, TP and TC indexes are defined below:

$$
\begin{gathered}
\mathrm{TP}=\frac{\mathrm{N}_{T}}{\mathrm{C}_{\mathrm{S}}} \\
\mathrm{TC}=\frac{S_{R}}{S}
\end{gathered}
$$

where $\mathrm{N}_{\mathrm{T}}, \mathrm{S}_{\mathrm{R}}$, $\mathrm{S}$ are number of traffic lights, area of main roads \& fast speed roads, total area in specific region, respectively.

Towards government users, GP and GC indexes are defined below:

$$
\begin{aligned}
\mathrm{GP} & =\frac{\mathrm{C}_{G}}{\mathrm{C}_{\mathrm{S}}} \\
\mathrm{GC} & =\mathrm{N}_{\mathrm{G}}
\end{aligned}
$$

where $\mathrm{C}_{\mathrm{G}}, \mathrm{N}_{\mathrm{G}}$ are annual electricity consumption of government departments, number of government departments in specific area, respectively.

\section{Fuzzy Assessment Method of Regional Supply Reliability Needs}

Among indexes listed in chapter 3, indexes HP, CP, IP, TP and GP reflect the electricity consumption scale of different sorts of users, they are used for calculation of weigh coefficients of corresponding sort of users and named index set W. Indexes HC, CC, IC, TC, GC reflect reliability need level of different sorts of users, they are used for calculating the fuzzy assessment array and named index set $C$.

All the indexes will be divided into 5 levels (Lv.1, Lv.2, Lv.3, Lv.4, and Lv.5) and level-related each index's membership corresponding to every level will be obtained based on fuzzy assessment method, where Lv.1 is top level and stands for highest reliability need. Among index i $(\mathrm{i}=1,2, \cdots \cdot 10)$, which in turn corresponds to the index in index set $\mathrm{W}$ and $\mathrm{C}$, set level standard value of every level for each single index, presented as $b_{i 1}$, $b_{i 2}, b_{i 3}, b_{i 4}, b_{i 5}$ here. Membership functions selected are listed as Equation (11)-(13) [4]. Level standard value of every level to various indexes depends on the situation.

$$
\begin{gathered}
r_{i 1}\left(g_{i}\right)=\left\{\begin{array}{c}
1, g_{i} \in\left[b_{i 1}, \infty\right) \\
\frac{g_{i}-b_{i 2}}{b_{i 1}-b_{i 2}}, g_{i} \in\left[b_{i 2}, b_{i 1}\right) \\
0, g_{i} \in\left[0, b_{i 2}\right)
\end{array}\right. \\
r_{i j}\left(g_{i}\right)=\left\{\begin{array}{c}
\frac{b_{i(j-1)}-g_{i}}{b_{i(j-1)}-b_{i j}}, g_{i} \in\left[b_{i j}, b_{i(j-1)}\right), j=2,3,4 \\
0, g_{i} \in\left[b_{i(j-1)}, \infty\right) \cup\left[0, b_{i(j+1)}\right), j=2,3,4 \\
\frac{g_{i}-b_{i(j+1)}}{b_{i j}-b_{i(j+1)}}, g_{i} \in\left[b_{i(j+1)}, b_{i j}\right), j=2,3,4
\end{array}\right. \\
r_{i 5}\left(g_{i}\right)=\left\{\begin{array}{c}
1, g_{i} \in\left[0, b_{i 5}\right) \\
\frac{b_{i 4}-g_{i}}{b_{i 4}-b_{i 5}}, g_{i} \in\left[b_{i 5}, b_{i 4}\right) \\
0, g_{i} \in\left[b_{i 4}, \infty\right)
\end{array}\right.
\end{gathered}
$$

where $r_{i j}\left(g_{i}\right)$ is index i's membership of Lv.j. Assessment array $\mathbf{R}$ is then gained with index set C's membership as shown in Equation (14).

$$
\mathbf{R}=\left[\begin{array}{c}
r_{11} r_{12} \cdots r_{1 m} \\
r_{21} r_{22} \cdots r_{2 m} \\
\vdots \\
r_{n 1} r_{n 2} \cdots r_{n m}
\end{array}\right] \mathrm{n}=5, m=5
$$

Towards indexes in set $\mathrm{W}$, their assessment level results can be obtained by biggest membership principle.

Biggest membership principle is applied in this way[5]: To each index $\mathrm{i}$,let its membership values of level 1 to level 5 are $m_{1}, m_{2}, m_{3}, m_{4}$ and $m_{5}$, respectively. If $m_{k}=$ $\max \left\{m_{j}\right\}, j=1-5$, then assessment level of index $i$ (named 
$\mathrm{d}_{\mathrm{i}}$ ) is $\mathrm{k}$, namely $\mathrm{d}_{\mathrm{i}}=\mathrm{k}$.

Then modified sequence-comparison method is to be introduced to obtain weight vector $\mathbf{K}=\left\{\mathrm{k}_{\mathrm{HP}}, \mathrm{k}_{\mathrm{CP}}, \mathrm{k}_{\mathrm{IP}}, \mathrm{k}_{\mathrm{TP}}\right.$, $\left.\mathrm{k}_{\mathrm{GP}}\right\}$ from set W's assessment level $\mathrm{dW}=\left\{\mathrm{d}_{\mathrm{HP}}, \mathrm{d}_{\mathrm{CP}}, \mathrm{d}_{\mathrm{IP}}\right.$, $\mathrm{d}_{\mathrm{TP}}, \mathrm{d}_{\mathrm{GP}}$, element positions in $\mathrm{W}$ and $\mathrm{K}$ keep the same. First to have elements in dW sorted from small to large, let them be $d W=\left\{d_{1}, d_{2}, \ldots, d_{5}\right\}$, then $K=\left\{k_{1}, k_{2}, \ldots, k_{5}\right\}$. Second, reference to Table 1, comparison coefficients between indexes can be determined as Equation (15)[5]:

$$
\mathrm{k}_{\mathrm{i}-1} / \mathrm{k}_{\mathrm{i}}=\mathrm{r}_{\mathrm{i}}(\mathrm{i}=5,4,3,2)
$$

Third, each weight of weight vector $\mathbf{K}$ can be calculated with Equation (16).

$$
k_{5}=\left(1+\sum_{m=2}^{5} \prod_{n=m}^{5} r_{n}\right)^{-1} k_{i-1}=r_{i} \cdot k_{i} \quad(i=5,4,3,2)
$$

With weight vector $\mathbf{K}$ obtained above, regional reliability needs membership D can be calculated with Equation (17).

$$
\mathbf{D}=\mathbf{K} \bullet \mathbf{R}=\left\{\mathrm{dA}_{1} \mathrm{dA}_{2} \mathrm{dA}_{3} \mathrm{dA}_{4} \mathrm{dA}_{5}\right\}
$$

According to biggest membership principle, regional reliability needs assessment level can be obtained. However, in order to utilize D's membership data[6], method to get comprehensive assessment score $\mathrm{G}$ is shown in Equation (18).

$$
\mathrm{G}=100 \cdot \mathrm{dA}_{1}+80 \cdot \mathrm{dA}_{2}+60 \cdot \mathrm{dA}_{3}+40 \cdot \mathrm{dA}_{4}+20 \cdot \mathrm{dA}_{5}
$$

\section{Application}

Level standard values of indexes and assessment data of 4 selected areas are listed in Table 2.

Area A is a residential area with high-percentage highrise buildings, and except high-percentage residential electricity consumption the consumption of other types is rather small. Except its low-percentage of high-rise buildings, Area B is similar to area A.

Area $\mathrm{C}$ is an ordinary industrial park with high-percentage industrial electricity consumption and there is only little amount of consumption of other types. Area D is a high-tech zone with the same percentage industrial electricity consumption as area $\mathrm{C}$, and its production value per unit consumption is very much.

Weight vectors of 4 selected areas are listed in Table 3. For area A and B, $k_{\mathrm{HP}}$ is bigger than other weights. For area $\mathrm{C}$ and $\mathrm{D}, \mathrm{k}_{\mathrm{IP}}$ is rather big due to the fact that industrial electricity consumption is major load of both areas. Therefore, modified sequence-comparison method works well and weight vectors correctly reflect features of selected areas.

Table 4 contains details of reliability need level about selected areas. Take area A for instance, membership of Lv.1 is quite large, but membership of other level is small. Some users require high quality of reliability and quite a few users' reliability need is ordinary or lower than the average. Otherwise, the scores point out reliability needs of selected area. Based on scores of area reliability needs, reliability need sorted results of selected areas in descending order is $\mathrm{D}>\mathrm{A}>\mathrm{C}>\mathrm{B}$. Such reliability needs assessment result may be good reference for power grid planners. Funds should be allocated to those areas with high scores of area reliability needs.

\begin{tabular}{|c|c|c|c|c|c|c|c|c|c|}
\hline \multirow{2}{*}{ Index } & \multicolumn{5}{|c|}{ Level standard values } & \multicolumn{4}{|c|}{ Area assessment data } \\
\hline & Lv.5 & Lv.4 & Lv.3 & Lv.2 & Lv.1 & A & B & $\mathrm{C}$ & $\mathrm{D}$ \\
\hline HC [\%] & 5 & 10 & 20 & 30 & 40 & 55 & 20 & 10 & 10 \\
\hline $\mathrm{HP}[\%]$ & 5 & 10 & 12 & 14 & 20 & 60 & 60 & 12 & 12 \\
\hline $\mathrm{CP}[\%]$ & 1.23 & 2.46 & 3.07 & 3.68 & 4.30 & 2 & 2 & 2.5 & 2.5 \\
\hline CC [yuan /kWh] & 73 & 145 & 181 & 218 & 254 & 140 & 140 & 140 & 140 \\
\hline IP [\%] & 30 & 50 & 70 & 80 & 90 & 10 & 10 & 80 & 80 \\
\hline IC [yuan /kWh] & 9 & 18 & 23 & 27 & 32 & 20 & 20 & 23 & 50 \\
\hline GP [\%] & 0.2 & 0.40 & 0.8 & 1.2 & 1.73 & 0.2 & 0.2 & 0.4 & 0.4 \\
\hline GC [1/sq.km.] & 2 & 3 & 4 & 5 & 6 & 4 & 4 & 4 & 4 \\
\hline $\mathrm{TC}[\mathrm{km} / \mathrm{km} 2]$ & 0.48 & 0.96 & 1.2 & 1.44 & 1.68 & 0.2 & 0.2 & 1.2 & 1.2 \\
\hline TP [1/sq.km.] & 0.5 & 1 & 2 & 5 & 10 & 1 & 1 & 2 & 2 \\
\hline
\end{tabular}

Table 1. Reference on determining $\mathbf{r}_{\mathbf{k}}$.

\begin{tabular}{cc}
\hline $\mathrm{r}_{\mathrm{k}}$ & Description \\
\hline 1.0 & $\mathrm{~d}_{\mathrm{k}-1}=\mathrm{d}_{\mathrm{k}}$ \\
1.5 & $\mathrm{~d}_{\mathrm{k}-1}-\mathrm{d}_{\mathrm{k}}=1$ \\
2.0 & $\mathrm{~d}_{\mathrm{k}-1}-\mathrm{d}_{\mathrm{k}}=2$ \\
2.5 & $\mathrm{~d}_{\mathrm{k}-1}-\mathrm{d}_{\mathrm{k}}=3$ \\
3.0 & $\mathrm{~d}_{\mathrm{k}-1}-\mathrm{d}_{\mathrm{k}}=4$ \\
\hline
\end{tabular}

Table 2. Level standard values of indexes and assessment data of 4 selected areas. 
Table 3. Weight vector results.

\begin{tabular}{ccccc}
\hline \multirow{2}{*}{ Index } & \multicolumn{5}{c}{ Area } \\
\cline { 2 - 5 } & $\mathrm{A}$ & $\mathrm{B}$ & $\mathrm{C}$ & $\mathrm{D}$ \\
\hline $\mathrm{k}_{\mathrm{HP}}$ & 0.43 & 0.43 & 0.21 & 0.21 \\
$\mathrm{k}_{\mathrm{CP}}$ & 0.17 & 0.17 & 0.14 & 0.14 \\
$\mathrm{k}_{\mathrm{IP}}$ & 0.11 & 0.11 & 0.31 & 0.31 \\
$\mathrm{k}_{\mathrm{GP}}$ & 0.11 & 0.11 & 0.14 & 0.14 \\
$\mathrm{k}_{\mathrm{TP}}$ & 0.17 & 0.17 & 0.21 & 0.21 \\
\hline
\end{tabular}

Table 4. Reliability need assessment results.

\begin{tabular}{ccccccc}
\hline \multirow{2}{*}{ Area } & \multicolumn{5}{c}{ Level membership } & \multirow{2}{*}{ Score } \\
\cline { 2 - 6 } & Lv.5 & Lv.4 & Lv.3 & Lv.2 & Lv.1 & \\
\hline A & 0.18 & 0.22 & 0.16 & 0.00 & 0.43 & 65.32 \\
B & 0.18 & 0.22 & 0.59 & 0.00 & 0.00 & 48.18 \\
C & 0.01 & 0.34 & 0.62 & 0.03 & 0.00 & 53.52 \\
D & 0.01 & 0.34 & 0.34 & 0.00 & 0.31 & 65.33 \\
\hline
\end{tabular}

\section{Conclusions}

A qualitative-data-based fuzzy assessment method for assessing regional supply reliability needs is presented in this paper. This method combines modified sequencecomparison method and its weight vector calculation utilizes objective indexes to avoid subjectivity. This method can help power grid planners to implement feasibility analysis.

\section{REFERENCES}

[1] Y. T. Song, D. X. Zhang, C.-H. Liang, et al., "Power Supply Reliability Planning for Urban Power Network of China Southern Power Grid,” Power System Technology, Vol. 33, No. 8, 2009, pp. 48-54 (in Chinese).

[2] J. Zhao, C. Q. Kang, Q. Xia, et al., "Power System Reliability in electricity Market Current S Tatus and Future Prospects," Automation of Electric Power Systems, Vol. 28, No. 5, 2004, pp. 6-10.

[3] P. Zhou, K. G. Xie, J. Q. Zhou, et al., "Reliability Power Price and Compensation Mechanism Adapted to Electricity Market Operation Environment," Automation of Electric Power Systems, Vol. 28, No. 21, 2004, pp. 6-11.

[4] H. X. Yang, K. G. Xie, K. Cao, et al., "Reliability Electricity Price Model for Power Market Considering Indicator Weight," Power System Protection and Control, Vol. 39, No. 16, 2011, pp. 67-73.

[5] Y. X. He, D. N. Liu, T. Lu, et al., "Power Comprehensive Evaluation Method and Its Application,” China Electric Power Press, Beijing, 2011, pp. 42-45.

[6] D. Du, Q. H. Pang and Y. Wu, "Modern Comprehensive Evaluation Method and Case Selection,” 2nd Edition, Tsinghua University Press, Beijing, 2008, pp.40. 